\title{
Independence of mitral valve prolapse and neurosis
}

\author{
ANDREW J HICKEY, GAVIN ANDREWS, DAVID E L WILCKEN
}

From the University Departments of Cardiovascular Medicine and Psychiatry, The Prince Henry Hospital, Sydney, Australia

SUMMARY An association has been claimed between mitral valve prolapse and the neuroses, especially the anxiety states, panic disorders, and agoraphobia. In this study 103 patients with echocardiographically confirmed mitral valve prolapse were tested with the Eysenck Personality Inventory for neuroticism and with the General Health Questionnaire for the presence of neurotic symptoms. The scores for neuroticism and neurotic symptoms were not significantly different from those of patients with other cardiac diseases or from those of patients presenting in primary care. In addition 50 patients with agoraphobia were screened by echocardiography for mitral valve prolapse, but no cases were detected. It appears that some of the earlier evidence for an association between mitral valve prolapse and neurosis may have been based on groups which were incorrectly diagnosed. It is concluded that mitral valve prolapse and neurosis are independent conditions.

Mitral valve prolapse occurs in about $5 \%$ of the adult population. ${ }^{12}$ Although patients in the community are usually symptom free, individuals presenting for echocardiography often complain of fatigue, dyspnoea, palpitations, syncope, and chest pain. These complaints are often vague and fleeting and may not be clearly related to disturbances in cardiac physiology. This lack of association between symptoms and physiology has led to the suggestion that the complaints of symptoms in mitral valve prolapse may be associated with neurotic behaviour, in particular the anxiety and panic disorders.

The number of reports of the positive association between panic attacks and mitral valve prolapse is rapidly increasing. Since the advent of criteria for the diagnosis of panic disorder ${ }^{3}$ it has been clear that the symptoms of panic disorder may be similar to those appearing in mitral valve prolapse. In many reports little consideration has been given to the possibility that these panic type symptoms in mitral valve prolapse could be secondary to the cardiac disorder itself and hence should not be diagnosed as the psychiatric condition of panic disorder.

There have been three studies from echocardiography laboratories 4- 6 which have reported panic attacks in patients with mitral valve prolapse and four studies of psychiatric populations ${ }^{7-10}$ in which patients with generalised anxiety disorder, panic disorder, or agoraphobia have been reported to show an increased prevalence of mitral valve prolapse. In this study we compared the incidence of neuroticism and neurotic Accepted for publication 31 May 1983 symptoms in a series of 170 cardiac patients with and without mitral valve prolapse and then examined the incidence of mitral valve prolapse in a series of $\mathbf{5 0}$ patients with agoraphobia.

\section{Patients and methods}

\section{DIAGNOSTIC PROCEDURES}

The diagnosis of mitral valve prolapse was confirmed by echocardiography. M-mode echocardiography was performed using an Irex Mark II echoscope (Irex Medical Systems, New Jersey) with a 2.25 MHz focused transducer. Both leaflets of the mitral valve and the left atrial wall posteriorly were identified as described by Markiewicz et al. ${ }^{11}$ Evidence of mitral valve prolapse was based on the recommendations of De Maria et al..$^{12}$ and Jeresaty. ${ }^{13}$ Our criteria for a positive diagnosis were, therefore, as follows: a mid to late systolic displacement of one or both leaflets at least $2 \mathrm{~mm}$ below the line joining the point of valve closure in systole (C) to the point of valve opening in diastole (D); or a pansystolic posterior displacement of at least $3 \mathrm{~mm}$ below the line joining $C$ and $D$ with the nadir occurring in mid-systole. When good quality M-mode echocardiographs could not be obtained, cross sectional echocardiography was performed using a Toshiba SSH10A Sonolayergraph. With this technique mitral valve prolapse was diagnosed using the criteria of Morganroth et al. ${ }^{14}$ Evidence of isolated ruptured chordae ${ }^{15}$ was also taken to be diagnostic of mitral valve prolapse. This issue will be discussed further. 
Neuroticism was estimated from scores on the neuroticism scale of the Eysenck Personality Inventory ${ }^{16}$ form A. Neurotic symptoms were estimated from scores on the 30 item General Health Questionnaire. ${ }^{17}$ Agoraphobia was diagnosed in accordance with the criteria of Spitzer. ${ }^{3}$ The diagnosis of each patient was confirmed by an independent assessor.

\section{STUDY POPULATION}

We studied 220 patients: in 103 mitral valve prolapse was confirmed as the primary diagnosis, 67 had other non-ischaemic cardiac disorder, and 50 agoraphobics were referred for screening for mitral valve prolapse.

\section{MITRAL VALVE PROLAPSE}

The 103 patients with mitral valve prolapse consisted of 48 men (mean age 53 years, range 25-78) and 55 women (mean age 46 years, range 23-74). Of the total group, 80 were referred because of symptoms suggesting the disorder. In a further 15 there were no complaints, the patient being referred because of ausculatory signs consistent with mitral valve prolapse but in this group symptoms were elicited on direct questioning. The final eight patients were truly symptom free being referred on account of signs only.

In retrospect 93 patients had a sufficient combination of symptoms and signs to permit a clinical diagnosis of mitral valve prolapse which was, of course, later confirmed by echocardiography. In the remaining 10 these features were unconvincing and echocardiography provided the only reliable evidence for mitral valve prolapse. At echocardiography 78 had late systolic prolapse and eight pansystolic mitral valve prolapse. Of these eight, four had isolated clicks, two had clicks and late systolic murmurs, and two had pansystolic murmurs. Twelve had ruptured chordae on cross sectional echocardiography, and anatomical and histological confirmation of myxomatous valve disease was available in all 12 . Five had mitral valve prolapse at cross sectional echocardiography, the $\mathrm{M}$-mode tracings being of insufficient quality to confirm prolapse. Of these five, four had pansystolic murmurs and one had a click with a late systolic murmur, signs supportive of the diagnosis.

\section{NON-ISCHAEMIC CARDIAC DISORDERS}

The control group consisted of 67 patients who were being examined echocardiographically for suspected or known chronic cardiac disease. Patients with ischaemic heart disease were excluded because of the known association between this condition and anxiety disorders. ${ }^{18}$ There were 33 men (mean age 45 years, range 18-77) and 34 women (mean age 48 years, range 23-75) in this group. Each of the 170 patients in the group with mitral valve prolapse and the control group completed both the Eysenck personality inventory and the general health questionnaire at the time of their echocardiography. As an additional comparison the Eysenck Personality Inventory and General Health Questionnaire scores for samples of primary practice attenders matched for age and sex were obtained from other local surveys. 1920

\section{AGORAPHOBIA}

The 50 agoraphobics were a consecutive series of patients who had been admitted to hospital for treatment of their agoraphobia. There were eight men (mean age 37 years, range $24-40$ ) and 42 women (mean age 36 years, range 21-67). Of these 50 patients, 43 reported palpitations as one of the symptoms of the panic attacks associated with their agoraphobia. Each agoraphobic patient underwent a cardiac and an echocardiographic examination and completed an Eysenck Personality Inventory.

Table Means and standaird errors (SEM) of the Eysenck Personality Inventory Neuroticism scores (EPIN) and the distributions of General Health Questionnaire (GHQ) scores for 103 patients with mitral valve prolapse, 67 patients with other heart disease, and 85 patients presenting in primary care

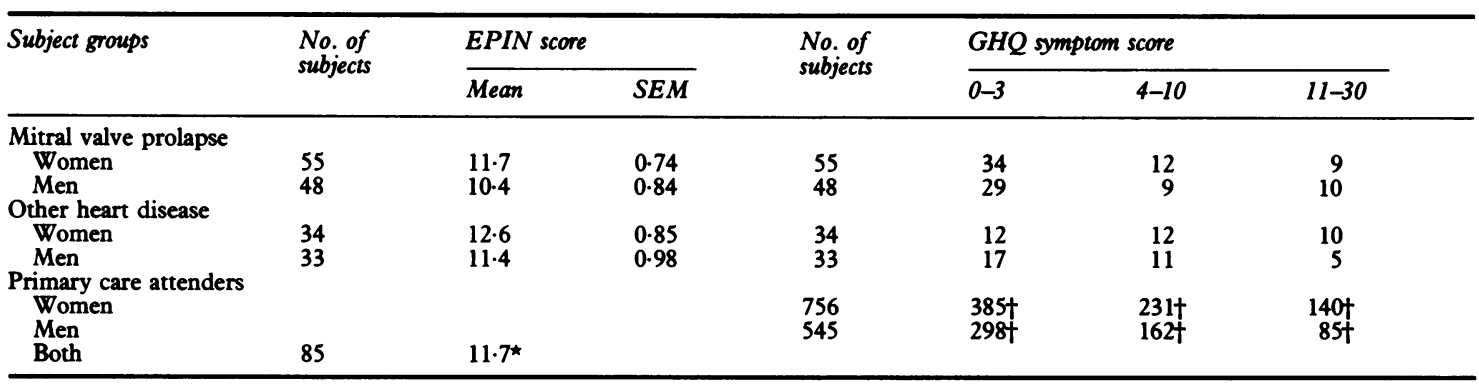

^Data from Parker and Tupling. ${ }^{20}$

+Data from Mant et al. ${ }^{19}$

Differences between the scores of patients with mitral valve prolapse and those of patients in the other two groups were not significant. 
Results

\section{NEUROTICISM}

No significant differences were found in the mean scores for either neuroticism or neurotic symptoms between the group with mitral valve prolapse and the control group with other cardiac disease (Table). The scores of both groups were similar to those of patients presenting in primary care. The scores of the patients who complained of symptoms of mitral valve prolapse but did not have sufficient pathology to require operation were examined to see if they were a group who would show an excess of neuroticism or neurotic symptoms: they were not.

None of the 50 patients who were being treated for agoraphobia had mitral valve prolapse according to our echocardiographic and clinical criteria. Four patients had systolic murmurs: one a pansystolic, two a mid-systolic, and one a late systolic murmur. No clicks were detected. The mean neuroticism score of these patients was 17.6 which was significantly different from that of 11.1 in the group with mitral valve prolapse $(\mathrm{p}<0.01)$.

\section{Discussion}

In this study there was no significant difference in neuroticism between 103 patients with mitral valve prolapse (the majority having symptoms) and a control group of 67 cardiac patients. Furthermore, there was no significant difference in neuroticism between the patients with mitral valve prolapse and those presenting in primary care centres. The neuroticism scores of all our groups were higher than those expected from a community sample, since all the groups consisted of patients whose symptoms would have had a small inflationary effect on trait neuroticism scores. ${ }^{21}$ Similarly, patients with mitral valve prolapse showed no more neurotic symptoms than did either the cardiac controls or the primary care patients.

It was interesting to note that of our 103 patients with mitral valve prolapse three complained of panic attacks, and one of these patients had secondary agoraphobia related to his confirmed cardiac disease. Pariser et al. ${ }^{7}$ were the first investigators to describe an association between panic attacks and mitral valve prolapse. Three further studies of patients with chronic anxiety disorders have reported a high incidence of mitral valve prolapse. 5910 Criticism of the diagnostic criteria for mitral valve prolapse by Ursano et al. ${ }^{22}$ has, however, cast doubt on the extent of this association for they state: "The isolated finding of a non-ejection click or holosystolic posterior mitral motion is only a possible indicator of mitral valve prolapse." When their guidelines are applied to some of the studies which claim an association between mitral valve prolapse and psychiatric symptoms we found a disturbing lack of detail. Pariser et al. ${ }^{7}$ said that six of 17 patients with panic attacks had "definite" mitral valve prolapse syndrome but the auscultatory findings and the echocardiographic features of these six patients were not reported. Venkatesh et al. ${ }^{5}$ reported that eight of 21 highly selected patients with "anxiety neurosis (panic disorder)" had mitral valve prolapse, but three of these did not have auscultatory features and four had pansystolic prolapse at echocardiography. It is not clear whether the three patients without auscultatory signs had pansystolic or late systolic prolapse. Most, therefore, had only inadequate evidence of mitral valve prolapse. It is of interest that when a further 26 patients with "chronic anxiety disorders" were examined at the same centre only one patient was shown to have mitral valve prolapse, ${ }^{23}$ a result consistent with the prevalence in the general population.

Further support for our findings comes from the second part of our study in which mitral valve prolapse was not found in any of our 50 patients with agoraphobia. Kantor et al. ${ }^{9}$ reported that eight of 25 patients with agoraphobia had positive echocardiographic features of mitral valve prolapse. If we apply the guidelines of Ursano et al. ${ }^{22}$ we note that only three of these eight had the required auscultatory signs. Furthermore, there are numerous reports ${ }^{24}$ which show that patients with agoraphobia may become symptom free after behaviour therapy and this would be difficult to achieve if an appreciable proportion of these patients were continuing to be affected by their cardiac condition.

The questionable accuracy of diagnosis of cases previously reported, and the present findings, based as they are on large carefully diagnosed samples of patients, clearly refute the notion ${ }^{25} 26$ that there is a common association between mitral valve prolapse and neurosis.

\section{References}

1 Hickey AJ, Wolfers J, Wilcken DEL. Mitral valve prolapse prevalence in an Australian population. Med $\mathcal{F}$ Aust 1981; 1: 31-3.

2 Procacci PM, Savran SV, Screiter SL, Bryson AL. Prevalence of clinical mitral valve prolapse in 1169 young women. $N$ Engl f Med 1976; 294: 1086-8.

3 Spitzer R. DSM-III case book: a leaming companion to the diagnostic and statistical manual of mental disorders. 3rd ed. Washington DC: American Psychiatric Association, 1981.

4 Shappell SD, Orr W, Gunn CG. The ballooning posterior leaflet syndrome. Minnesota Multiphasic Personality Inventory profiles in symptomatic and asymptomatic groups. Chest 1974; 66: 690-2. 
5 Venkatesh A, Pauls D, Crowe R, et al. Mitral valve prolapse in anxiety neurosis (panic disorder). Am Heart $\mathfrak{f}$ 1980; 100: 302-5.

6 Crowe RR, Gaffney G, Kerbey R. Panic attacks in families of patients with mitral valve prolapse. Fournal of Affective Disorders 1982; 4: 121-5.

7 Pariser SF, Jones BA, Pinta ER, Young EA, Fontana ME. Panic attacks: diagnostic evaluations of 17 patients. Am f Psychiatry 1979; 136: 105-6.

8 Venkatesh A, Pauls DL, Crowe R, et al. Mitral valve prolapse in patients with anxiety neurosis. Clin Res 1978; 53: 464-73.

9 Kantor JS, Zitrin CM, Zeldis SM. Mitral valve prolapse syndrome in agoraphobic patients. Am F Psychiatry 1980; 137: 467-9.

10 Grunhaus L, Gloger S, Rein A, Lewis BS. Mitral valve prolapse and panic attacks. Isr F Med Sci 1982; 18: 2213.

11 Markiewicz W, Stoner J, London E, Hunt SA, Popp RL. Mitral valve prolapse in one hundred presumably healthy young females. Circulation 1976; 53: 464-73.

12 DeMaria AN, King JF, Bogren HG, Lies JE, Mason DT. The variable spectrum of echocardiographic manifestations of the mitral valve prolapse syndrome. Circulation 1974; 50: 33-41.

13 Jeresaty RM. Mitral valve prolapse. New York: Raven Press, 1979.

14 Morganroth J, Jones RH, Chen CC, Naito M. Two dimensional echocardiography in mitral, aortic and tricuspid valve prolapse. Am F Cardiol 1980; 46: 1164 77.

15 Mintz GS, Kotler MN, Segal BL, Parry WR. Twodimensional echocardiographic recognition of ruptured chordae tendineae. Circulation 1978; 57: 244-50.

16 Eysenck HJ, Eysenck SBG. Personality structure and measurement. San Diego: Knapp, 1969.

17 Goldberg DP. The detection of psychiatric illness by questionnaire. London: Oxford University Press, 1972.

18 Byrne D. Anxiety as state and trait following survived myocardial infarction. Br $\mathcal{F}$ Soc Clin Psychol 1979; 18: 417-23.

19 Mant A, Duncan-Jones P, Andrews G, Chancellor A. General practice survey. Report to Royal Australian College of General Practitioners, Sydney, NSW, 1976.

20 Parker G, Tupling $H$. The chiropractic patient: psychosocial aspects. Med $\mathcal{F}$ Aust 1976; 2: 373-8.

21 Osborne D. Use of the MMPI with medical patients. In: Butcher JN, ed. New development in the use of the MMPI. Minneapolis: University of Minnesota Press, 1979: 159.

22 Ursano RJ, Jones DR, Corcoran JFT. Mitral valve prolapse and psychiatric symptoms [Letter]. Am F Psychiatry 1981; 138: 258-9.

23 Kathol RG, Noyes R, Slymen DJ, Crowe RR, Clancy J, Kerber RE. Propranolol in chronic anxiety disorders. Arch Gen Psychiatry 1980; 37: 1361-5.

24 Munby M, Johnston DW. Agoraphobia: the long term follow-up of behavioural treatment. Br F Psychiatry 1980; 137: 418-27.

25 Wooley CF. Where are the diseases of yesteryear? Da Costa's syndrome, soldiers heart, the effort syndrome, neurocirculatory asthenia - and the mitral valve prolapse syndrome. Circulation 1976; 5: 749-51.

26 Leatham A, Brigden W. Mild mitral regurgitation and the mitral prolapse fiasco. Am Heart f 1980; 99: 659-64.

Requests for reprints to Dr Andrew Hickey, School of Medicine, Clinical Sciences Building, The Prince Henry Hospital, Sydney, New South Wales 2036, Australia. 